\title{
Abnormalities in Glucose Blood Level during Antipsychotic Treatment in Schizophrenia Patients
}

\author{
Faisal Idrus, Theodorus Singara, Dwiwahyu Sunarto* (D), Saidah Syamsuddin (D), Sonny T. Lisal \\ Department of Psychiatry, Faculty of Medicine, Hasanuddin University, Makassar, Indonesia
}

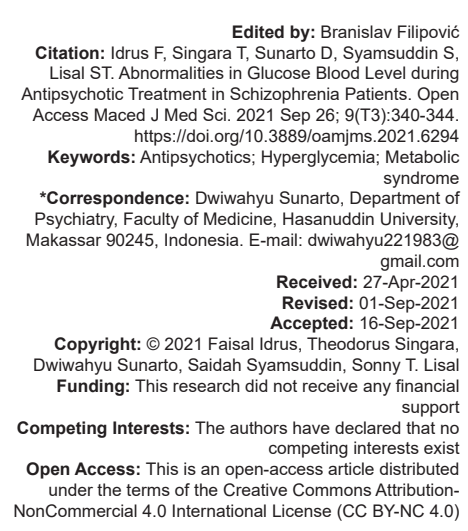

Introduction

Schizophrenia is one of the mental disorders with major problematic issues, both psychologically and socially. It is now well established that people with serious mental illness, including schizophrenia, have excess morbidity and mortality, leading to a reduced life span of 20-25 years compared with the rest of the population [1]. The increased mortality is largely attributable to physical illness, including metabolic abnormalities, rather than factors that are directly associated with psychiatric illness such as suicide or homicide [2]. Metabolic syndrome occurs in one in three patients and diabetes in one in five patients [3]. People with schizophrenia have an increased risk of diabetes and other metabolic abnormalities. A renewed interest in this phenomenon has been sparked by the adverse metabolic effects of antipsychotic medications used in the treatment of schizophrenia.

Antipsychotics with their potent dopamine antagonist properties are most often used to treat schizophrenia. Antipsychotics are categorized as first-generation antipsychotics (typical) and secondgeneration antipsychotics (atypical). Several studies have reported abnormal glucose metabolism during antipsychotic drug (APD) treatment. Antipsychotics caused $37 \%$ prediabetes and $10 \%$ diabetes [4]. Meanwhile, in animal study [5] reported that risperidone and haloperidol also caused significant increases in fasting glucose and/or insulin levels at the high dose, $60 \mathrm{~min}$ post-drug administration. In this study, we would like to determine the acute effects of metabolic (hyperglycemia) in patients treated with antipsychotic, haloperidol, and risperidone.

In the preliminary study, hyperglycemia condition in new patients occurs in four in seven patients who received typical and atypical antipsychotics. Recent attention has also been focused on antipsychoticinduced hyperglycemic emergencies experienced by new users of typical and atypical antipsychotic. Patients treated with atypical APDs have $\sim 10$ times higher risk in developing hyperglycemic emergencies [6]. In this study, we would like to determine the acute effects of metabolic (hyperglycemia) in patients treated with antipsychotic (risperidone and haloperidol). 


\section{Methods}

This research is a cohort prospective study, it was conducted in the psychiatry ward of the Special Regional Hospital of South Sulawesi Province in Makassar, from January to March 2019. The ethical approval was granted by the hospital and by Hasanuddin University. The samples were patients who were diagnosed with schizophrenia (295.) according to the Diagnostic and Statistical Manual of Mental Disorders fifth edition (DSM V). Informed consent was obtained from each sample, the consent given by the closest family member or guardian to patients who were considered unable to participate.

\section{Subject}

A total of 30 subjects who met the inclusion criteria were collected for this study. The inclusion criteria were: Age between 18 and 50 years old, diagnosis of schizophrenia by DSM V. All therapy are carried out by the psychiatric in charge of the ward. Meanwhile, the exclusion criteria: Subject with medical conditions that could confound glucose-regulatory assessments, including history of diabetes mellitus and other organic mental disorder, and subjects with a body mass index (BMI) above normal (for women: $17-23 \mathrm{~kg} / \mathrm{m}^{2}$ and for men: $18-25 \mathrm{~kg} / \mathrm{m}^{2}$ )

In this study, we divided the subjects into two groups. The first group $(n=15)$ was schizophrenic patients who used haloperidol at therapeutic dose 5-15 mg. Moreover, the second group $(n=15)$ was schizophrenic patients who used risperidone at therapeutic doses 2-6 mg. All subjects were examined for blood sugar level after meals and fasting blood sugar at the beginning of treatment, week IV, and week VIII.

\section{Assessment}

In this study, there were 2 measurements of blood sugar carried out on the subject. The first was the measurement of blood sugar after meal and the second one was the measurement of blood sugar after $8 \mathrm{~h}$ fasting before breakfast. The $8 \mathrm{~h}$ of fasting was to ensure that the results were not affected by the consumption of the last meal. The results of blood sugar levels are interpreted according to the criteria of the American Diabetic Association [7].

\section{Statistical analysis}

Comparison between blood sugar levels after meal and fasting blood sugar levels were analyzed by Mann-Whitney test. To determine changes in blood sugar levels after meal and fasting blood sugar levels after 4 and 8 weeks of treatment in both groups were analyzed by Wilcoxon, Marked Rank. Data analysis was performed using SPSS version 22. Statistical significance level was defined as a $p<0.05$.

\section{Results}

This study was performed to determine changes in glucose blood level during antipsychotics treatment in schizophrenia patients. A total of 30 samples who met the inclusion criteria were selected.

Demographic characteristics of subjects were revealed and compared in Table 1. The schizophrenia group included a total of 30 (13 males and 17 females). The presentation of subjects with 17-40 years old was significantly higher. Most of the samples were patients who had been out of the drug for more than 3 months, and the highest duration of illness period was $1-5$ years.

Table 1: Sociodemographic characteristics of the subjects

\begin{tabular}{lll}
\hline Patients characteristics & $\mathrm{n}=30$ & Percentage \\
\hline Age & & \\
17-40 years old & 19 & 63.3 \\
40-50 years old & 11 & 36.7 \\
Gender & & \\
$\quad$ Male & 13 & 43.3 \\
$\quad$ Female & 17 & 56.7 \\
Marital status & & \\
$\quad$ Married & 22 & 73.3 \\
$\quad$ Currently Single & 8 & 26.6 \\
Occupation & & \\
$\quad$ Employed & 13 & 43.3 \\
$\quad$ Unemployed & 17 & 56.6 \\
Drop out medicine for at least 3 months & 22 & 73.3 \\
$\quad$ New patients & 8 & 26.7 \\
Durration of illness (years) & & \\
$\quad<1$ & 8 & 26.7 \\
1-5 & 13 & 43.3 \\
\hline
\end{tabular}

Table 2 shows that there was a significant increase in the risperidone group based on examination of fasting blood sugar level collected data at week VIII compared to week IV, with $\mathrm{p}(<0.001)$, and similarly with the haloperidol group. Statistically, risperidone increases fasting blood sugar level compared with haloperidol.

Table 2: Blood level sugar after meal

\begin{tabular}{lllllll}
\hline Group & Variable & $\mathrm{n}$ & Mean & $\mathrm{SD}$ & $\%$ & $\mathrm{p}$ \\
\hline Haloperidol & Beginning treatment & 15 & 84.7 & 2,5 & $2.8(3.3)$ & 0.001 \\
& Week IV & 15 & 87.5 & 2.3 & & \\
& Beginning treatment & 15 & 84.7 & 2,5 & $6.1(7.2)$ & 0.001 \\
& Week VIII & 15 & 90.8 & 2.0 & & \\
& Week IV & 15 & 87.5 & 2.3 & $3.3(3.8)$ & 0.001 \\
& Week VIII & 15 & 90.8 & 2.0 & & \\
Risperidon & Beginning treatment & 15 & 87.5 & 2.7 & $3.0(3.4)$ & 0.002 \\
& Week IV & 15 & 90.5 & 1.6 & & \\
& Beginning treatment & 15 & 87.5 & 2.7 & $13.4(15.2)$ & 0.001 \\
& Week VIII & 15 & 100.9 & 3.4 & & \\
& Week IV & 15 & 90.5 & 1.6 & $10.4(11.4)$ & 0.001 \\
& Week VIII & 15 & 100.9 & 3.4 & & \\
\hline
\end{tabular}

Table 3 shows that there was a significant increase in the risperidone group based on examination of blood sugar level after meal collected data at week VIII compared to week IV, with $\mathrm{p}(<0.001)$, and similarly with the haloperidol group. Statistically, risperidone increases blood sugar level after meal compared with haloperidol. 
Table 3: Fasting blood level sugar

\begin{tabular}{lllllll}
\hline Group & Variable & $\mathrm{n}$ & Mean & $\mathrm{SD}$ & $\%$ & $\mathrm{p}$ \\
\hline Haloperidol & Beginning treatment & 15 & 83 & 2,9 & $3.3(4.0)$ & 0.001 \\
& Week IV & 15 & 86.3 & 2.7 & & \\
& Beginning treatment & 15 & 83 & 2.9 & $5.7(6.9)$ & 0.001 \\
& Week VIII & 15 & 88.7 & 2.3 & & \\
& Week IV & 15 & 86.3 & 2.7 & $2.4(2.8)$ & 0.002 \\
& Week VIII & 15 & 88.7 & 2.3 & & \\
Risperidon & Beginning treatment & 15 & 83.7 & 2,4 & $3.0(3.6)$ & 0.001 \\
& Week IV & 15 & 86.7 & 2.2 & & \\
& Beginning treatment & 15 & 83.7 & 2,7 & $15.6(18.7)$ & 0.001 \\
& Week VIII & 15 & 99.3 & 3.4 & & \\
& Week IV & 15 & 86.7 & 2.2 & $12.6(14.5)$ & 0.001 \\
& Week VIII & 15 & 99.3 & 3.4 & & \\
\hline
\end{tabular}

Figure 1 shows there was a significant increase in blood sugar levels after meal in the risperidone group compared to the haloperidol group which was 87.5 compared to 84.7 ( $p<0.001)$. Week IV was significantly higher in the risperidone group than in the haloperidol group, which was 90.5 compared to 87.5 $(p<0.001)$. Week VIII was significantly higher in the risperidone group than in the haloperidol group, which was $(p<0.001)$.

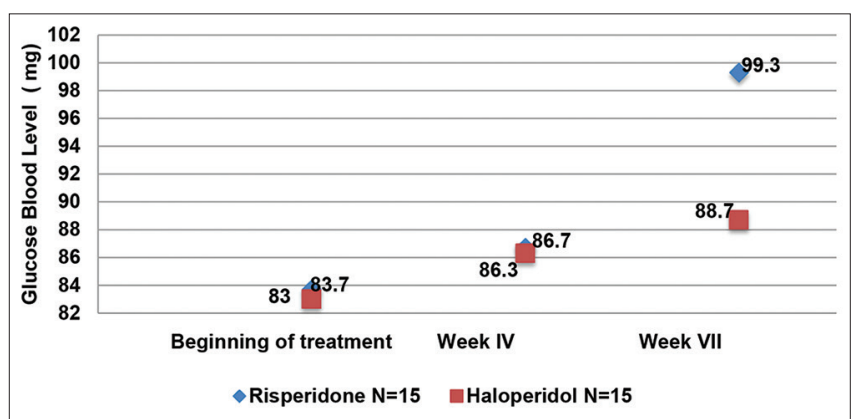

Figure 1: Fasting blood sugar level

Figure 2 shows there was a significant increase in fasting blood sugar levels at week VIII in the risperidone group compared to the haloperidol group which was 99.3 compared to 88.7 ( $p<0.001$ ).

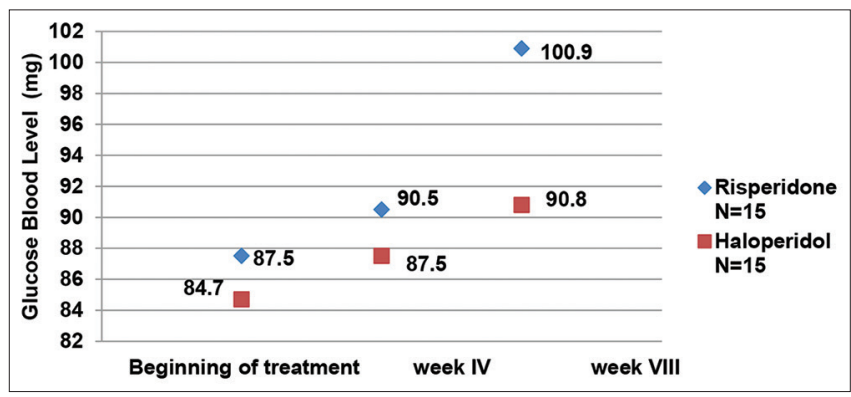

Figure 2: Blood level sugar after meal

\section{Discussion}

The main finding of the study was that risperidone treatment increased the blood sugar level significantly compared to haloperidol after 8 weeks. To the best of our knowledge, there is no such study in literature from this region (Special Regional Hospital of South Sulawesi Province, in Makassar) before.
Blood sugar levels showed a significant increase at week IV and week VIII in both of haloperidol and risperidone group. The results of blood sugar levels are interpreted according to the criteria of the American Diabetic Association.

This is consistent with the research conducted by Wani in 2015 [8]. Understanding the mechanisms for antipsychotics-induced diabetes should be helpful in the prevention and treatment of these side effects and thus improve the clinical outcomes of antipsychotic treatment. Antipsychotic-induced diabetes could be mediated by multiple mechanisms: (1) Antipsychotic can inhibit the insulin signaling pathway in the target cells such as muscle cells, hepatocytes, and adipocytes to cause insulin resistance [9], [10] (2) antipsychoticinduced obesity can result in high levels of free fatty acids and inflammation, which can also cause insulin resistance [11], [12], [13] and (3) antipsychotic can cause direct damage to $\beta$-cells, leading to dysfunction and apoptosis of $\beta$-cells. A recent theory considers that both $\beta$-cell damage and insulin resistance are necessary factors for the development of diabetes. In high-fat-diet-induced diabetes, the compensatory ability of $\beta$-cells is gradually damaged, while antipsychotic causes direct $\beta$-cell damage, accounting for the severe form of antipsychotic-induced diabetes. Based on these mechanisms, effective prevention of antipsychoticinduced diabetes may need an integrated approach to combat various effects of antipsychotic on multiple pathway [14], [15].

Interestingly, we found that the risperidone group showed a significant increase of blood sugar level compared to the haloperidol group after 8 weeks. Some previous studies found that in most patients, hyperglycemia occurs within 3 months after the start of risperidone therapy, with relatively higher amounts [16].

Aswe know, risperidone causes insulin resistance through obesity. Risperidone is an antipsychotics that blocks receptors 5-HT2C, histamine $\mathrm{H} 1$, and D2 receptors resulting in a decrease in proopiomelanocortin anorexigenic and an increase in NPY production, leading to increased appetite [17], [18], [19]. Thus, our observation that risperidone induces more glucose dysregulation than haloperidol (typical antipsychotics) may be explained by differential receptor occupancy.

However, because there is more evidence of the effects of hyperglycemia, as evidenced by our study, prescription choices now must be based on assessing the efficacy of each drug and its potential to cause movement disorders or metabolic side effects. Psychiatrists, primary care doctors, and other mental health professionals must know well about glucose dysregulation associated with antipsychotics. Before starting treatment with antipsychotic agents, especially risperidone, it is very important to check the family history of type 2 diabetes mellitus, obtain basic body weight/BMI, plasma glucose levels, and lipid profiles. Weight/BMI must be monitored at each visit; plasma glucose levels should be checked 
at 8 weeks follow-up, according to our observations. Schizophrenia patients who are most often potential diabetics are associated with risk factors such as lifestyle, smoking habits, and poor nutrition. Such patients should be encouraged to take a low carbohydrate and high protein diet with lots of vegetables. They are also advised to do physical activity for at least 30 min, 3 times a week. If the patients have high fasting blood sugar that leads to diabetes mellitus type 2 diagnosis, we suggested to change the antipsychotics to another antipsychotic agent that has more minimal metabolic effects with an equivalent dose.

\section{Conclusions}

Thus, we conclude that antipsychotic treatment (haloperidol and risperidone) can be associated with adverse effects on glucose regulation in 4 weeks based on blood sugar level after meal data and in 8 weeks based on fasting blood sugar examination data.

In the previous study, the researchers measured fasting blood sugar at the beginning of treatment, weeks 6 and week 14. Where in the first 6 weeks, there were dysregulated blood sugar levels induced by antipsychotics (olanzapine, risperidone, haloperidol, and aripiprazole). Hence, in this study, the researchers tried to examined blood sugar levels early and periodically within 4 weeks-8 weeks.

Timely blood glucose monitoring and advice on a healthy lifestyle can reduce the risk of glucose dysregulation triggered by antipsychotics.

\section{Authors' Contributions}

All the authors were involved in the conception of this study FI, TS, SS, and SL to interpretation of the research findings and contributed to the drafting of the manuscript. All authors read and approved the final manuscript.

\section{Acknowledgments}

The author would like to thanks participants who volunteered for this study and the students who participated in the data collection. The authors would like to acknowledge the important support and contributions of Arifin Seweng, M.D as our statistics lecturer.

\section{Ethics Approval and Consent to Participate}

The research has been permitted and acknowledged by Hasanuddin University Ethic Medical Committee (267/UN4.6.4.5.31/PP36/2019). Before each interview, each participant was given written information on the study. Each participant was also informed that his or her participation was voluntary. Before each interview, we emphasized the importance of maintaining confidentiality in relation to patient cases. All participants provided written consent to participate in the study.

\section{Availability of Data and Materials}

The datasets used and analyzed for this study are available from the corresponding author on reasonable request.

\section{References}

1. Mitchell AJ, Vancampfort D, Sweers K, Van Winkel R, Yu W, De Hert M. Prevalence of metabolic syndrome and metabolic abnormalities in schizophrenia and related disorders-a systematic review and meta analysis. Schizophr Bull. 2013;39(2):306-18. https://doi.org/10.1093/schbul/sbr148 PMid:22207632

2. Best L, Yates AP, Reynolds GP. Actions of antipsychotic drugs on pancreatic $\beta$-cell function: Contrasting effects of clozapine and haloperidol. J Psychopharmacol 2005;19(6):597-60. https:// doi.org/10.1177/0269881105056641

PMid:16272180

3. Khalil RB. Atypical antipsychotic drugs, schizophrenia, and metabolic syndrome in non-Euro-American societies. Clin Neuropharmacol. 2012;35(3):141-7. https://doi.org/10.1097/ wnf.0b013e31824d5288

PMid:22592510

4. Boucher J, Kleinridders A, Kahn CR. Insulin receptor signaling in normal and insulin-resistant states. Cold Spring Harb Perspect Biol. 2014;6(1):a009191. https://doi.org/10.1101/cshperspect. a009191

5. Boyda HN, Tse L, Procyshyn RM, Wong D, Wu TK, Pang CC et al. A parametric study of the acute effects of antipsychotic drugs on glucose sensitivity in animal model. Prog Neuropsychopharmacol Biol Psychiatry. 2010;34(6):945-54. https://doi.org/10.1016/j.pnpbp.2010.04.024 PMid:20452386

6. Brown S. Excess mortality of schizophrenia. A meta-analysis. $\mathrm{Br}$ J Psychiatry. 1997;171:502-8.

PMid:9519087

7. Deng C. Effects of antipsychotic medications on appetite, weight, and insulin resistance. Endocrinol Metab Clin North Am 2013;42(3):545-63. 


\section{PMid:24011886}

8. Engl J, Laimer M, Niederwanger A, Kranebitter M, Starzinger M, Pedrini $\mathrm{M}$, et al. Olanzapine impairs glycogen synthesis and insulin signaling in L6 skeletal muscle cells. Mol Psychiatry. 2005;10(12):1089-96. https://doi.org/10.1038/sj.mp.4001729 PMid:16130009

9. Han M, Deng C, Burne TH, Newell KA, Huang XF. Short-and longterm effects of antipsychotic drug treatment on weight gain and $\mathrm{H} 1$ receptor expression. Psychoneuroendocrinology. 2008;33(5):56980. https://doi.org/10.1016/j.psyneuen.2008.01.018 PMid:18358632

10. Elizabeth AK. Risperidone-associated diabetes mellitus: A pharmacovigilance study. Pharmacotherapy. 2003;23(6):735-44. PMid:12820816

11. Longo DL, Fausi AS, Kasper DL, Hauser SL, Jameson JL, Loscalzo J. Harrison's : Principles of Internal Medicine. $17^{\text {th }}$ ed. New York: McGraw-Hill Medical; 2008. https://doi. org/10.1111/j.1445-5994.2008.01837.x

12. Colton CW, Manderschied RW. Congruencies in increased mortality rates, years of potensial life lost, and causes of death among public mental health client in eight states. Prev Chronic Dis. 2006;2(2):A42.

PMid:16539783

13. Manu P, Correl CU, van Winkel R, Wampers M, De Hert M. Prediabetes in patients treated with antipsychotic drugs. J Clin Psychiatry. 2012;73(4): 460-6. https://doi.org/10.4088/ jcp.10m06822 PMid:22225552

14. Matsui-Sakata A, Ohtani H, Sawada Y. Receptor occupancybased analysis of the contributions of various receptors to antipsychotics-induced weight gain and diabetes mellitus. Drug Metab Pharmacokinet. 2005;20(5):368-78. https://doi. org/10.2133/dmpk.20.368

PMid:16272755

15. Ozasa R, Okada T, Nadanaka S, Nagamine T, Zyryanova A, Harding $\mathrm{H}$, et al. The antipsychotic olanzapine induces apoptosis in insulin-secreting pancreatic $\beta$ cells by blocking PERK-mediated translational attenuation. Cell Struct Funct. 2013;38(2):183-95. https://doi.org/10.1247/csf.13012

PMid:23812432

16. Wani RA, Dar MA, Margoob MA, Rather YH, Haq I, Shah MS Diabetes mellitus and impaired glucose tolerance in patients with schizophrenia, before and after antipsychotic treatment. J Neurosci Rural Pract. 2015;6(1):17-22. https://doi. org/10.4103/0976-3147.143182

17. Ferno J, Varela L, Skrede $S$, Vazquez MJ, Nogueiras $R$, Dieguez C, et al. Olanzapine-induced hyperphagia and weight gain associate with orexigenic hypothalamic neuropeptide signaling without concomitant AMPK phosphorylation. PLoS One. 2011;6(6):e20571. https://doi.org/10.1371/journal. pone.0020571

PMid:21695181

18. Fleischhacker WW, Siu CO, Bodén R, Pappadopulos E, Karayal ON, Kahn RS. Metabolic risk factors in first-episode schizophrenia: Baseline prevalence and course analysed from the European first-episode schizophrenia trial. Int $J$ Neuropsychopharmacol. 2013;16(5):987-95. https://doi. org/10.1017/s1461145712001241

PMid:23253821

19. Foley DL, Morley KI. Systematic review of early cardiometabolic outcomes of the first treated episode of psychosis. Arch Gen Psychiatry. 2011;68(6):609-16. https://doi.org/10.1001/ archgenpsychiatry.2011.2

PMid:21300937 